Article

\title{
The Effects of Iodine Fortified Milk on the Iodine Status of Lactating Mothers and Infants in an Area with a Successful Salt Iodization Program: A Randomized Controlled Trial
}

\author{
Pantea Nazeri ${ }^{1}$, Parvin Mirmiran ${ }^{1,2, *}$, Zhale Tahmasebinejad ${ }^{1}$, Mehdi Hedayati ${ }^{3}$, \\ Hossein Delshad ${ }^{4}$ and Fereidoun Azizi ${ }^{4, *}$ \\ 1 Nutrition and Endocrine Research Center, Research Institute for Endocrine Sciences, \\ Shahid Beheshti University of Medical Sciences, 19395-4763 Tehran, Iran; nazeri.pantea@gmail.com (P.N.); \\ jtahmasebinejad@yahoo.com (Z.T.) \\ 2 Department of Nutrition and Clinical Dietetics, Faculty of Nutrition Sciences and Food Technology, \\ National Nutrition and Food Technology Research Institute, Shahid Beheshti University of \\ Medical Sciences, 19395-4741 Tehran, Iran \\ 3 Cellular and Molecular Research Center, Research Institute for Endocrine Sciences, \\ Shahid Beheshti University of Medical Sciences, 19395-4763 Tehran, Iran; hedayati47@yahoo.com \\ 4 Endocrine Research Center, Research Institute for Endocrine Sciences, Shahid Beheshti University of \\ Medical Sciences, 19395-4763 Tehran, Iran; delshad1336@yahoo.com \\ * Correspondence: mirmiran@endocrine.ac.ir (P.M.); Azizi@endocrine.ac.ir (F.A.); \\ Tel.: +98-21-2235-7483 (P.M.); +98-21-2243-2503 (F.A.); Fax: +98-21-2240-2463 (F.A.)
}

Received: 20 December 2016; Accepted: 17 February 2017; Published: 22 February 2017

\begin{abstract}
Iodine deficiency during the first two years of life may cause irreversible brain damage and mental retardation. The aim of the present study was to investigate, for the first time, the effect of iodine fortified milk on the iodine status of lactating mothers and their infants. In this multicenter randomized controlled trial, 84 lactating mother-infant pairs from health care centers were randomly selected. After meeting the inclusion criteria, lactating mothers were randomly assigned to two groups: the iodine fortified milk group and the control group ( $n=42$ each). Maternal and infant urine and breast milk samples were collected at 3-5 (baseline), 7, 10, 14 days, and 1 month postpartum, for a measurement of the iodine concentration. A total of 84 lactating mothers, with a mean age of $28.2 \pm 4.5$ years, and 84 infants, with a mean age of $4.2 \pm 0.7$ days, were included in the study. Compared to mothers of the control group, mothers receiving iodine fortified milk had higher urinary $(p<0.001)$ and breast milk $(p<0.001)$ iodine concentrations. Urinary iodine levels in infants revealed no significant differences between the two groups. The findings of this study indicate that supplementation with daily iodine fortified milk provides iodine nutrition adequacy among lactating mothers. However, it had no effect on the iodine status of infants, who were previously iodine sufficient.
\end{abstract}

Keywords: iodine status; lactating mothers; infants; iodine fortified milk; urinary iodine; breast milk iodine

\section{Introduction}

Iodine, as an essential component of thyroid hormones, is vital for normal growth and the development of most organs, especially the brain [1,2]; hence, iodine deficiency during the first few years of life can lead to developmental delays, irreversible brain damage, and mental retardation [3-6]. Based on the United Nations Children's Fund (UNICEF) estimation, over thirty five million newborns 
currently remain unprotected against the lifelong consequences of brain damage associated with iodine deficiency [7].

It is now well recognized that iodized salt is the best way of guaranteeing an adequate amount of iodine in the diet, and this is the most effective approach for the control of iodine deficiency disorders (IDD) in almost all countries worldwide [8,9]; however, concerted efforts are currently being made in many countries to reduce salt intake, for the prevention of cardiovascular diseases and hypertension, which raises the concern that decreasing salt consumption will increase the risk of iodine deficiency [10-13]. In addition, it appears that, in some countries/areas, iodine requirements of the most susceptible groups, including pregnant and lactating women, might not always be adequately met by iodized salt [14-16]. On the other hand, as seen in most industrial countries, where only a part of the population actually consumes iodized salt, the increase in the urinary iodine concentration (UIC) of the population mainly depends on the presence of iodine in foods, viz. milk and dairy products. It has been shown that in several countries, such as the USA, New Zealand, Australia, Canada, Denmark, Belgium, Norway, and Germany, milk is a good vehicle for an adequate iodine intake [17-24]. Surveys on individual consumption reveal that the frequency of milk consumption is associated in a dose dependent manner with their urinary iodine concentrations $[25,26]$.

In the Islamic Republic of Iran, which was recognized as an area of iodine deficiency, the production and nationwide consumption of iodized salt containing 20-40 ppm iodine began in 1990, and became mandatory for household consumption by 1994. Since then, national surveys conducted every 3-5 years have shown a sustainable elimination of iodine deficiency disorders among schoolchildren. Although Iran was declared to be free of iodine deficiency in the year $2000[27,28]$, decreasing the intake of iodized salt as the main dietary iodine source has been accompanied by an increased percentage of subjects with insufficient iodine status [12], and hence, considering dietary iodine sources other than iodized salt is essential for vulnerable groups, specifically lactating mothers with higher iodine requirements. Moreover, despite the recommendations of major societies i.e., the American Thyroid Association and the Endocrine Society [29-31], the need for iodine supplementation in lactating mothers in Iran with a sustainable elimination of IDD over the past two decades, has not been yet evaluated. Therefore, the present study was designed to investigate the effect of iodine fortified milk on the provision of iodine adequacy among lactating mothers and their infants, in an area with a successful salt iodization program.

\section{Materials and Methods}

\subsection{Subjects}

In this multicenter randomized controlled trial, conducted in the southern region of Tehran, four health care centers responsible for newborn screenings were randomly selected. In each health care center, on the first visit and at the time of screening for congenital hypothyroidism (within 3-5 days postpartum), 20 lactating mothers and their infants were enrolled for participation in this study, if they met the following inclusion criteria: Healthy mothers and their infants had no history of thyroid disorders, were not currently using iodine containing supplements and disinfectants, had had a singleton birth and intended to exclusively breast feed; infants were born full-term (gestational age, 37-42 weeks) with an age of 3-5 days and a normal birth weight (2500-4200 g), and at that point in time ( $3-5$ days), had normal serum thyrotropin in the neonatal screening program. Maternal information on the age, education, occupation, date of last pregnancy, gravidity, parity, history of abortion in previous pregnancies, use of iodine-containing supplements during pregnancy, and the type of delivery were documented, and demographic information on the newborn, including, birth of date, sex, and birth weight, height, and head circumference measurements, was obtained using an interviewer-administrated questionnaire. Written informed consent was obtained after the study protocol and objectives were fully explained to all lactating mothers and/or their husbands. The present study was approved by the ethics committee of the Research Institute for Endocrine Sciences (RIES), 
Shahid Beheshti University of Medical Sciences. This clinical trial has been registered in the Iranian registry of Clinical Trials at http:/ / www.irct.ir with the following identification: IRCT20135074794N9.

\subsection{Intervention}

After meeting the inclusion criteria, lactating mothers were randomly assigned to one of two groups: iodized salt as the control group $(n=42)$ and the iodine fortified milk $(n=42)$ group, using a random number table. This randomization was conducted by a researcher who was not directly involved in the data collection. For an equal allocation to the two groups, the direction for reading the table was predetermined as the right and an arbitrary starting point was selected. Then, the researcher equated the odd and even numbers to the intervention and control groups, respectively. If mothers were lactose tolerant, they were assigned to the control group. In the control and iodine fortified milk groups, mothers received recommendations to use only iodized salt during cooking and as table salt. In the iodine fortified milk group, each mother received a box containing 15 tetra pack packets of sterilized milk every two weeks and was instructed to consume a packet of milk daily, with breakfast or the morning snack; $200 \mathrm{~mL}$ of which provided $150 \mu \mathrm{g}$ iodine/day. Mothers were also asked to drink the milk directly, without heating it, since the process of heating may alter the iodine content of iodine fortified milk. All participants were telephoned weekly to ensure that the iodized salt and/or iodine fortified milk were consumed. The intervention in this study was started at the sixth day postpartum and lasted for four weeks. Compliance was evaluated by counting the empty packets and weekly follow-up phone calls.

To provide iodine fortified milk, organic cows' milk was fortified by supplementing cattle feed with potassium iodide as the source of iodine [32,33]. Milk was sterilized for six months of its shelf life and then packaged into $200 \mathrm{~mL}$ portion packets. Ten tetra pack packets of sterilized milk were randomly chosen from different boxes and tested for quality control by the iodine laboratory of the Endocrine Research Center (ERC), the reference laboratory of the Eastern Mediterranean region. All packets of milk contained a mean iodine content (range) of $155(151-160) \mu \mathrm{g} / 200 \mathrm{~mL}$.

\subsection{Urine and Milk Samples Collection}

At the first visit, labeled plastic bottles and adhesive pediatric urine bags (SUPA medical services, Tehran, Iran) were provided, to collect spot urine samples of each lactating mother and their infant at 3-5 (baseline), 7, 10, 14 days, and 1 month postpartum, at any time during the day, according to the detailed instructions provided; they were also instructed to clean the genital region of the newborns and to place the entire penis in the bag, attaching the adhesive to the skin for boys and to fit the bag over the labia for girls. If urine samples of newborns could not be collected using an adhesive urine bag after three attempts, mothers were asked to do this by holding a specimen bottle in the urine stream. Mothers were also asked to manually express their breast milk at the same time points as these urine collections. At each time point, all urine and milk samples were collected and sent to the iodine laboratory of the ERC, and were transferred in screw-top labeled plastic vials. The aliquots were kept frozen at $-20^{\circ} \mathrm{C}$, until the iodine concentrations were measured.

\subsection{Salt Sample Collection}

Two tablespoon salt samples, used during cooking and/or as table salt, were collected from each of the mothers at 3-5 days (baseline), and 1 month postpartum; some mothers used two types of salt (i.e., iodized salt and sea salt, or iodized salt and rock salt), for which samples of both were collected. The samples were kept in lightproof, closed plastic cans and labeled with the code for each mother.

\subsection{Laboratory Measurements}

The iodine concentration in urine and milk samples was analyzed using the Sandell-Kolthoff (acid-digestion) reaction [34,35] and results were expressed as micrograms of iodine per liter of urine and milk. Milk samples were carefully homogenized before the alkaline ashing procedure. Intra-assay 
coefficients of variation (CV) at UIC values of $8.5,17.5$, and $36.0 \mu \mathrm{g} / \mathrm{L}$, were $8.5 \%, 6.2 \%$, and $8.0 \%$, respectively. The inter-assay CV at concentrations of $8.5,17.4$, and $36.4 \mu \mathrm{g} / \mathrm{L}$, were $10.3 \%, 9.7 \%$, and $8.0 \%$, respectively. The intra-assay CV at breast milk iodine concentration (BMIC) values of 3.5, 12.7, and $36.2 \mu \mathrm{g} / \mathrm{L}$, were $8.6 \%, 6.7 \%$, and $9.3 \%$, respectively. The inter-assay CV at concentrations of $3.3,12.9$, and $35.7 \mu \mathrm{g} / \mathrm{L}$, were $9.8 \%, 8.6 \%$, and $12.3 \%$, respectively. The iodine concentration of salt samples was determined using the iodometric titration method, with $1 \mathrm{ppm}$ sensitivity and $1 \% \mathrm{CV}$. The obtained values are shown in ppm.

\subsection{Definition}

In lactating women and infants, according to international criteria, a median UIC $<100$ and $\geq 100 \mu \mathrm{g} / \mathrm{L}$, is representative of deficient and sufficient urinary iodine, respectively [8]. Adequate BMIC was considered to be 150-180 $\mu \mathrm{g} / \mathrm{L}$ [36].

\subsection{Statistics Analysis}

Based on our previous data on the median UIC in Tehranian women of childbearing age [12], to detect the change in the median UIC of $35 \mu \mathrm{g} / \mathrm{L}$ using a standard deviation (SD) of $55 \mu \mathrm{g} / \mathrm{L}$ with $90 \%$ power and a 2 -side alpha $=0.05$, and taking into account $30 \%$ attrition, at least 40 lactating mothers and their infants would be needed to be recruited into each of the iodized salt and iodine fortified milk groups.

The frequency distribution (percentage), mean $\pm \mathrm{SD}$, and median (interquartile range (IQR)) were expressed according to categorical and continuous variables. Normality of the variables was assessed by the Kolmogorov-Smirnove test and a histogram chart. Chi-square and Mann-Whitney ort-tests were used to assess the significance of differences for categorical and continuous variables in lactating mothers and infants. Linear mixed model analysis was used to assess the effect of iodine fortified milk on maternal and infant urinary and breast milk iodine concentrations. Three skewed outcome variables were log-transformed before analysis. For each continuous outcome variable, a separate mixed model was derived with the time and group as fixed effects, and participants as the random effect. Factors considered in the maternal UIC analysis were: Maternal UIC at baseline, mothers' job, gravidity, use of iodine containing supplements, and iodine content of salt. For the infant UIC analysis, besides the five maternal factors, an additional three factors (i.e., birth weight, infant UIC at baseline, and use of formula during the study period) were also considered. Statistical analyses were completed using IBM SPSS for windows (version 20.0, 2011, IBM Corp., Armonk, NY, USA) and the R-3.0.2 statistical programming environment using the nlme package, with $p$ values $<0.05$ being considered as significant.

\section{Results}

The flow of participants through the study is shown in Figure 1. Of a total 112 mother-infant pairs who initially enrolled, 28 mother-infant pairs declined to participate. Out of the eligible mothers who were willing to collaborate in this study, only three participants were lactose intolerant. A total of 84 mother-infant pairs were randomly allocated to the iodine fortified milk group and control group, ( $n=42$ each). Two weeks after supplementation, two mother-infant pairs were excluded from the intervention group, due to severe infant reflux and refusing to participate in the study; in the control group, one mother-infant pair was excluded, due to infant icter and hospitalization. Both study groups were followed for the following two weeks, during which one mother-infant pair was excluded from the control group; eventually, the data of 80 mother-infant pairs was made available for the current analysis ( $n=40$ each).The compliance rate was $94.7 \%$ in the intervention group.

At the baseline, the mean \pm SD age of the mothers and infants were $28.2 \pm 4.5$ years and $4.2 \pm 0.7$ days, respectively. There were no significant differences in the maternal and infant baseline characteristics of the two groups, with regard to the following factors: Maternal age, education, date of last pregnancy, gravidity, parity, type of delivery, history of abortion, use of iodine containing 
supplements during pregnancy and neonatal sex, birth weight, height, head circumference, and thyrotropin concentration (Table 1). When focusing on the salt samples collected during the study period, the median iodine content ranged from 25.0 at the baseline, to $25.8 \mathrm{ppm}$ at one month postpartum. No significant differences were found in the iodine content of salt between the two groups at the baseline and follow-up.

The BMIC and UIC of the mothers and infants, and the proportions of mothers and infants with an UIC $\geq 100$, and a BMIC $\geq 150 \mu \mathrm{g} / \mathrm{L}$, in the iodine fortified milk and control groups during the period of the study, are shown in Table 2. Maternal and infant median (IQR) UICs at 3-5 days (baseline) were 70.2 (41.2-199.0) and $231.2(91.7-268.2) \mu \mathrm{g} / \mathrm{L}$ in the iodine fortified milk group and 96.9 (47.1-193.8) and 192.8 (79.4-244.6) $\mu \mathrm{g} / \mathrm{L}$ in the control group, respectively. On the basis of their median UIC at the baseline, $35.9 \%$ and $45.7 \%$ of mothers, and $72.2 \%$ and $61.5 \%$ of infants, in intervention and control groups had an UIC $\geq 100 \mu \mathrm{g} / \mathrm{L}$, respectively. No significant differences in maternal and infant UICs at the baseline were found between the two groups. The median (IQR) BMIC was 176.0 (133.7-218.7) $\mu \mathrm{g} / \mathrm{L}$ in the iodine fortified milk group and $215.0(168.5-315.5) \mu \mathrm{g} / \mathrm{L}$ in the control group, indicating statistically significant differences between the two groups $(p=0.027)$. At $3-5$ days postpartum, the percentage of BMIC $\geq 150 \mu \mathrm{g} / \mathrm{L}$ was found in $65.0 \%$ and $81.0 \%$ of mothers of the intervention and control groups, respectively.

Table 1. Baseline characteristics of lactating mothers and their infants in the iodine fortified milk and control groups.

\begin{tabular}{|c|c|c|c|}
\hline Characteristics & $\begin{array}{l}\text { Iodine Fortified } \\
\text { Milk }(n=42)\end{array}$ & Control $(n=42)$ & $p$ \\
\hline \multicolumn{4}{|l|}{ Maternal } \\
\hline Age (year) & $27.7 \pm 4.5$ & $28.5 \pm 4.5$ & 0.356 \\
\hline Education (year) & $10.8 \pm 2.6$ & $11.2 \pm 3.7$ & 0.355 \\
\hline Occupation (housekeeper), $n(\%)$ & $40(95.2)$ & $38(92.7)$ & 0.625 \\
\hline Time ofprior pregnancy (year) & $3.1 \pm 3.6$ & $3.4 \pm 3.6$ & 0.774 \\
\hline Gravidity, $n(\%)$ & & & 0.524 \\
\hline Primigravidity & $17(40.5)$ & $11(26.8)$ & \\
\hline Multigravidity & $25(59.5)$ & $30(73.2)$ & \\
\hline Parity, $n(\%)$ & & & 0.546 \\
\hline Primiparity & $20(47.6)$ & $17(41.5)$ & \\
\hline Multiparity & $22(52.4)$ & $24(58.5)$ & \\
\hline Delivery type, $n(\%)$ & & & 0.690 \\
\hline NVD & $14(33.3)$ & $12(29.3)$ & \\
\hline CS & $28(66.7)$ & $29(70.7)$ & \\
\hline History of abortion, $n(\%)$ & & & 0.261 \\
\hline Yes & $7(16.7)$ & $11(26.8)$ & \\
\hline No & $35(83.3)$ & $30(73.2)$ & \\
\hline Use of iodine containing supplements during pregnancy, $n(\%)$ & & & 0.485 \\
\hline Yes & $3(7.1)$ & $2(4.9)$ & \\
\hline No & $29(69.0)$ & $33(80.5)$ & \\
\hline Do not know & $10(23.8)$ & $6(14.6)$ & \\
\hline \multicolumn{4}{|l|}{ Neonatal } \\
\hline Sex, $n(\%)$ & & & 0.708 \\
\hline Male & $26(61.9)$ & $27(65.9)$ & \\
\hline Female & $16(38.1)$ & $14(34.1)$ & \\
\hline Birth weight $(\mathrm{g})$ & $3187 \pm 344$ & $3251 \pm 348$ & 0.603 \\
\hline Birth height (cm) & $49.7 \pm 1.9$ & $50.0 \pm 1.7$ & 0.657 \\
\hline Birth head circumference $(\mathrm{cm})$ & $34.8 \pm 1.2$ & $34.5 \pm 1.5$ & 0.468 \\
\hline TSH (mIU/L) & $1.5 \pm 1.7$ & $1.2 \pm 1.1$ & 0.350 \\
\hline
\end{tabular}

NVD: natural vaginal delivery; CS: cesarean section; TSH: thyroid stimulating hormone. 


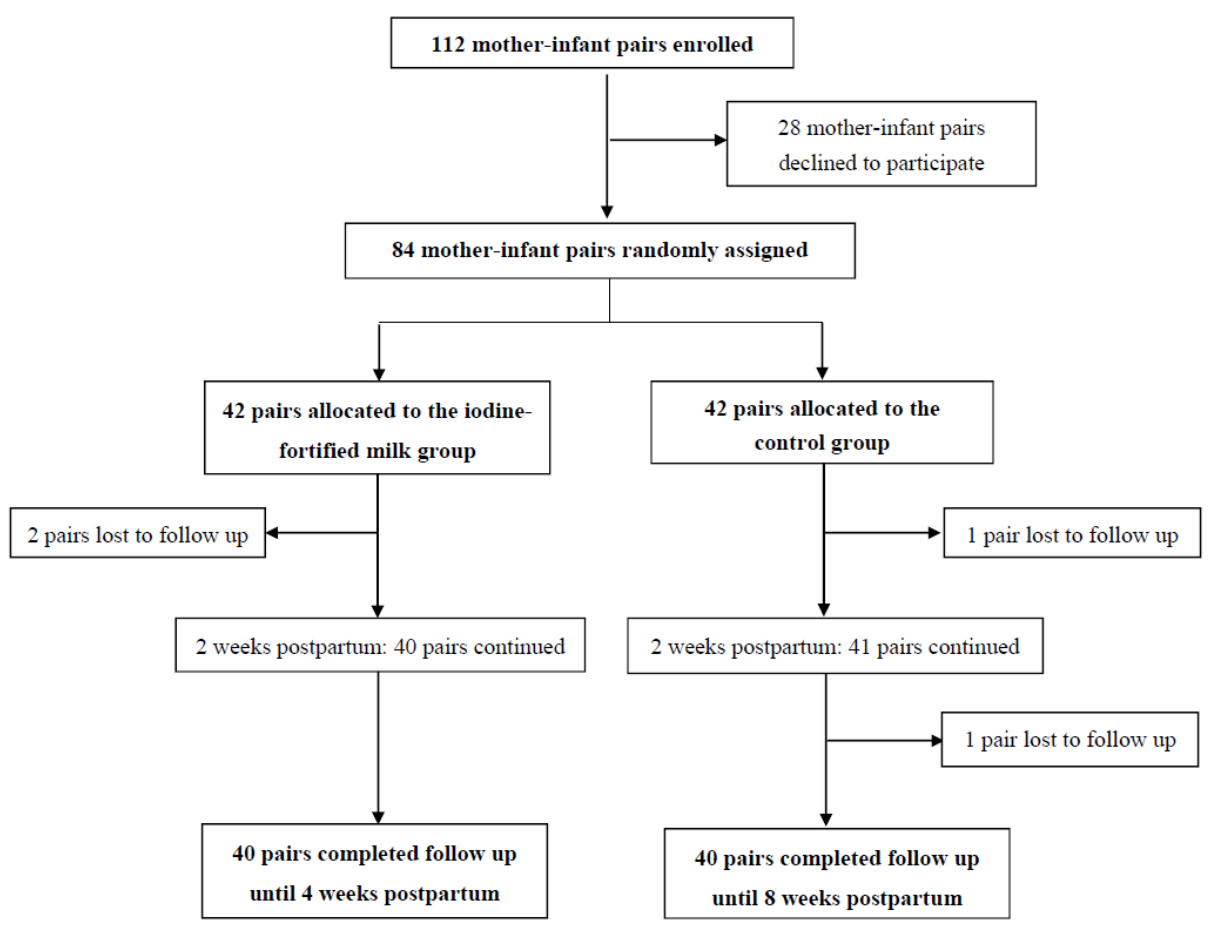

Figure 1. The study profile at a glance.

Table 2. Urinary and breast milk iodine concentrations in lactating mothers and their infants in the iodine fortified milk and control groups.

\begin{tabular}{|c|c|c|c|c|}
\hline \multirow{2}{*}{ Time Postpartum } & \multicolumn{2}{|c|}{ Iodine Fortified Milk $(n=40)$} & \multicolumn{2}{|c|}{ Control $(n=40)$} \\
\hline & Median (IQR) & $n(\%) *$ & Median (IQR) & $n(\%) *$ \\
\hline \multicolumn{5}{|l|}{ Maternal UIC $(\mu g / L)$} \\
\hline 3-5 days (baseline) & $70.2(41.2-199.0)$ & $14(35.9)$ & $96.9(47.1-193.8)$ & $16(45.7)$ \\
\hline 7 days & $118.7(68.0-161.7)^{* *}$ & $23(59.0) * *$ & $51.0(38.2-77.8)$ & $6(15.8)$ \\
\hline 10 days & $131.7(85.3-188.4)$ & $26(74.3)$ & $103.4(88.6-140.7)$ & $18(60)$ \\
\hline 14 days & $122.8(77.2-182.9)^{* *}$ & $23(60.5)^{* *}$ & $47.5(38.4-86.8)$ & $5(12.2)$ \\
\hline 1 month & $104.1(57.3-160.9)$ & $16(55.2)$ & $41.1(32.1-55.9)$ & $2(5.1)$ \\
\hline \multicolumn{5}{|l|}{ BMIC $(\mu g / L)$} \\
\hline 3-5 days (baseline) & $176.0(133.7-218.7)^{* *}$ & $26(65.0)$ & $215.0(168.5-315.5)$ & $34(81.0)$ \\
\hline 7 days & $191.0(105.0-245.0)$ & $27(65.9)$ & $176.0(140.0-286.0)$ & $28(71.8)$ \\
\hline 10 days & $217.0(148.7-339.0)^{* *}$ & $29(74.4)$ & $162.0(120.0-206.5)$ & $22(55.0)$ \\
\hline 14 days & $242.0(156.2-355.7)^{* *}$ & $30(78.9)$ & $160.0(115.2-199.2)$ & $23(60.5)$ \\
\hline 1 month & $210.0(100.0-286.0)^{* *}$ & $25(64.1)$ & $142.0(92.2-197.2)$ & 19 (47.5) \\
\hline \multicolumn{5}{|l|}{ Infant UIC $(\mu g / L)$} \\
\hline 3-5 days (baseline) & $231.2(91.7-268.2)$ & $13(72.2)$ & $192.8(79.4-244.6)$ & $16(61.5)$ \\
\hline 7 days & $168.7(86.2-326.4)$ & $18(75.0)$ & $120.0(69.7-219.3)$ & $16(64.0)$ \\
\hline 10 days & $218.9(138.4-293.1)^{* *}$ & $17(85.0)$ & $138.3(60.0-191.5)$ & $16(61.5)$ \\
\hline 14 days & $194.3(122.1-306.0)^{* *}$ & $24(80.0)^{* *}$ & $115.7(75.2-223.3)$ & $22(56.4)$ \\
\hline 1 month & $230.2(71.0-317.5)^{* *}$ & $14(73.7)$ & $110.4(47.2-197.0)$ & $19(52.8)$ \\
\hline
\end{tabular}

UIC: urinary iodine concentration; BMIC: breast milk iodine concentration; IQR: interquartile range. ${ }^{*}$ Normal values: urinary iodine concentration $\geq 100 \mu \mathrm{g} / \mathrm{L}$ and breast milk iodine concentration $\geq 150 \mu \mathrm{g} / \mathrm{L}$; ${ }^{* *}$ Significantly different from control group.

At the follow-up, the median (IQR) UIC of mothers in the intervention group increased from $70.2(41.2-199.0) \mu \mathrm{g} / \mathrm{L}$ at the baseline, to 104.1 (57.3-160.9) $\mu \mathrm{g} / \mathrm{L}$ at one month, although this was not significant; however, this value significantly decreased in mothers of the control group, from 96.9 (47.1-193.8) $\mu \mathrm{g} / \mathrm{L}$ at the baseline, to $41.1(32.1-55.9) \mu \mathrm{g} / \mathrm{L}$ at one month $(p<0.001)$. The median (IQR) maternal UIC in the control group remained below the $100 \mu \mathrm{g} / \mathrm{L}$ cutoff for iodine deficiency at all time 
points, except at 10 days postpartum (Figure 2A). Infants of mothers receiving iodine fortified milk had a median UIC ranging from 231.2 (91.7-268.2) to 230.2 (71.0-317.5) $\mu \mathrm{g} / \mathrm{L}$, demonstrating no significant difference over the intervention period, i.e., between three and five days, and one month postpartum $(p=0.339)$. However, the median (IQR) UIC decreased in the infants of mothers assigned to the control group, ranging from 192.8 (79.4-244.6) to 110.4 (47.2-197.0) $\mu \mathrm{g} / \mathrm{L}$ throughout the study's duration $(p=0.097)$ (Figure 2B). The median (IQR) BMIC gradually increased from $176.0(133.7-218.7) \mu \mathrm{g} / \mathrm{L}$ at the baseline, to 210.0 (100.0-286.0) $\mu \mathrm{g} / \mathrm{L}$ at one month, in mothers who received iodine fortified milk $(p=0.107)$; this value ranged from $215.0(168.5-315.5) \mu \mathrm{g} / \mathrm{L}$ at the baseline, to $142.0(92.2-197.2) \mu \mathrm{g} / \mathrm{L}$ at one month, in mothers of the control group $(p<0.001)$ (Figure $2 \mathrm{C}$ ).

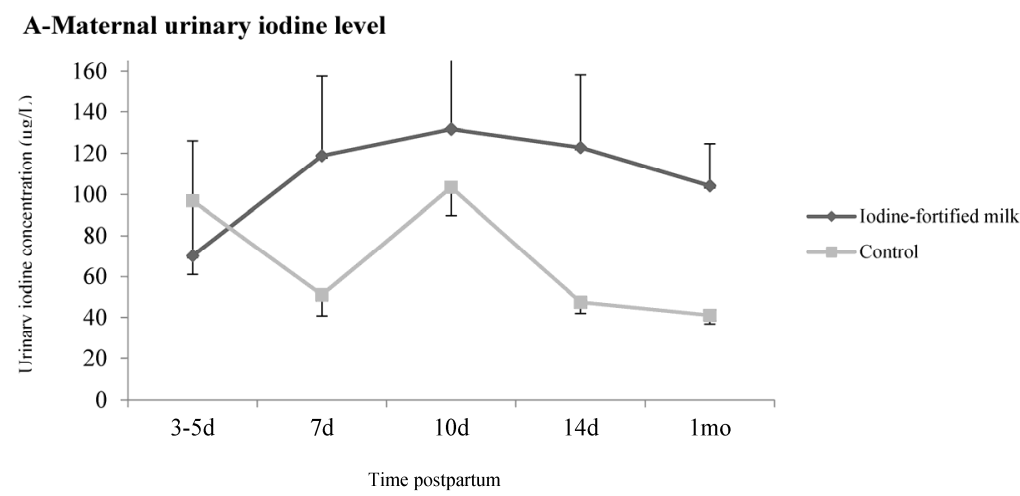

B-Infant urinary iodine level

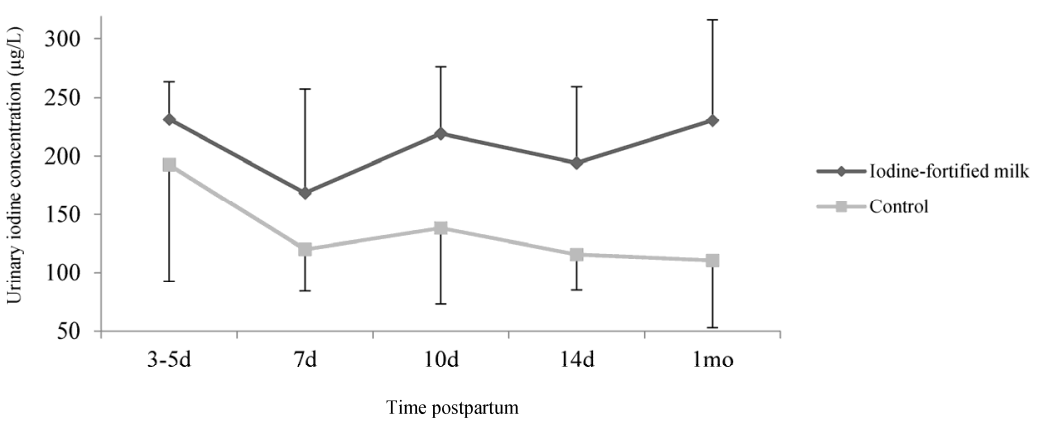

C- BMIC

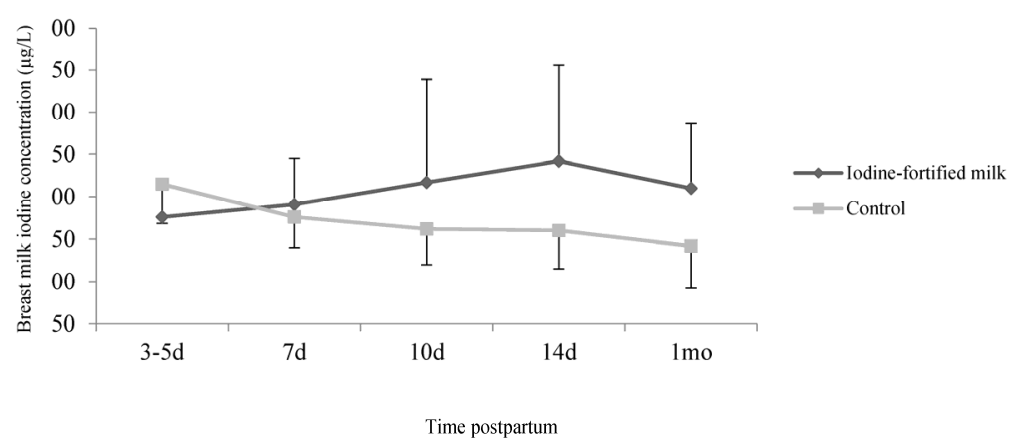

Figure 2. The effect of iodine fortified milk on maternal and infant urinary and breast milk iodine concentrations. (A) Urinary iodine concentration $(\mu \mathrm{g} / \mathrm{L}$ ) of mothers; (B) urinary iodine concentration $(\mu \mathrm{g} / \mathrm{L})$ of infants and $(\mathrm{C})$ breast milk iodine concentration $(\mu \mathrm{g} / \mathrm{L})$. Data are presented as the median and error bars are the differences between the median, and the 1st and 3rd quartiles.

The effects of iodine fortified milk on maternal and infant UIC and BMIC, using the mixed-model analysis, are presented in Table 3. In lactating mothers who received iodine fortified milk, the UIC values improved significantly, when compared to the control group $(p<0.001)$. After further adjustment of the baseline maternal UIC, differences between the two groups remained significant $(p<0.001)$. 
Infant UICs increased significantly in the intervention group, compared to the control group; however, after an adjustment of the baseline infant UICs, no significant difference was found between the two groups over the course of the study. In mothers supplemented with iodine fortified milk, there was no significant increase in the BMIC values, when compared with the control group $(p=0.096)$; however, after further adjustment of the baseline values, significant increases were observed in the BMIC of mothers in the iodine fortified milk group $(p<0.001)$.

Table 3. Effects of iodine fortified milk on maternal and infant urinary and breast milk iodine concentrations.

\begin{tabular}{ccc}
\hline Variables & Ratio of Means (95\% CI) ${ }^{*}$ & $p^{* *}$ \\
\hline Maternal urinary iodine concentration $^{*}$ & & \\
\hline Model I $^{\dagger}$ & $1.58(1.53-1.65)$ & $<0.001$ \\
Model II $^{\ddagger}$ & $1.85(1.77-1.93)$ & $<0.001$ \\
\hline Breast milk iodine concentration $^{*}$ & 0.096 \\
\hline Model I $^{\dagger}$ & $1.11(1.07-1.16)$ & $<0.001$ \\
\hline Model II $^{\ddagger}$ & $1.25(1.19-1.32)$ & \\
\hline Infant urinary iodine concentration $^{*}$ & & 0.021 \\
\hline Model I $^{\S}$ & $1.31(1.24-1.38)$ & 0.400 \\
\hline
\end{tabular}

CI: confidence interval. * Ratio of means $(95 \% \mathrm{CI})$ with log-transformed data; ** Linear mixed models were used to compare two groups for overall means during the period of study; ${ }^{\dagger}$ Adjusted for mothers' occupation, gravidity, use of iodine containing supplements during pregnancy, and iodine content of salt; ‡ Further adjusted for mothers' occupation, gravidity, use of iodine containing supplements during pregnancy, iodine content of salt, and baseline values; $\S^{\S}$ Adjusted for mothers' occupation, gravidity, use of iodine containing supplements during pregnancy, iodine content of salt, birth weight, and frequency use of formula; ${ }^{\ell}$ Further adjusted for mothers' occupation, gravidity, use of iodine containing supplements during pregnancy, iodine content of salt, birth weight, frequency use of formula, and baseline values.

\section{Discussion}

To the best of our knowledge, this is the first study assessing the effect of iodine fortified milk on the iodine status of lactating mothers and infants in an area with a successful salt iodization program. Findings of the current study indicate that the supplementation of lactating mothers with iodine fortified milk improved maternal urinary iodine to an adequate status. The breast milk iodine concentration in mothers receiving iodine fortified milk was significantly higher than in those of the control group. In addition, the mean urinary iodine level of previously iodine sufficient infants, whose mothers received iodine fortified milk, did not show any significant differences, when compared to the control infants.

The importance of milk and dairy products for the provision of adequate iodine is well-known; however, less information is available concerning the iodine content of milk, which meets the daily requirements of iodine in different age groups. Several studies have shown that the iodine concentration in milk varies between different countries and has changed significantly over the years. For instance, in Boston, the mean iodine concentration in milk was reported to be $45.4 \mu \mathrm{g} / 100 \mathrm{~mL}$ [22]. In England, the median iodine content was $14.5 \mu \mathrm{g} / 100 \mathrm{~g}$ in organic milk and $25.0 \mu \mathrm{g} / 100 \mathrm{~g}$ in non-organic milk [37], while data from Spain indicated a mean content of $25.9 \mu \mathrm{g} / 100 \mathrm{~mL}$ [26], and in Italy, a median value of $26.4 \mu \mathrm{g} / 100 \mathrm{~mL}$ was reported [38]. Data from Germany showed an increasing trend from 2004 to 2010 for the iodine content in milk; likewise, in Spain, the iodine content increased between 1991 and 2008 [39].

In Australia, the amount of iodine in milk reduced from $59.3 \mu \mathrm{g} / \mathrm{mL}$ in 1975 , to $19.5 \mu \mathrm{g} / \mathrm{mL}$ in 2004, which can be explained by chlorine-containing sanitizers replacing iodine-containing sanitizers in the dairy industry, resulting in a lower iodine content of milk [21]. The United Kingdom (UK) never introduced a formal iodization program to ensure optimal iodine status, but increased advertising 
and promotion, and a rise in the consumption of organic milk resulted in an exacerbation of the mild iodine deficiency in the country $[37,40]$. A recent study conducted in Shahrekord, in central Iran, showed that the mean iodine content of milk in semi- and industrial dairy farms was 14.8 and $31.4 \mu \mathrm{g} / 100 \mathrm{~mL}$, respectively [41]; however, due to a low daily per capita consumption of milk (<half of the recommended), it is not yet considered a main dietary iodine source among Iranian populations.

In countries where milk and dairy products are the main sources of dietary iodine, a higher milk iodine concentration and increased milk consumption have been cited as the reasons for the eradication of iodine deficiency. A strong association has been found between milk intake and urinary iodine excretion in several cross-sectional and follow-up studies [23,42,43]. Since milk is an appropriate source of iodine in children, findings of studies conducted in schoolchildren have demonstrated that those who consumed milk more often had higher urinary iodine concentrations [26]. However, few studies have addressed the role of cow milk as a source of iodine during pregnancy and/or lactation [44-46]. Moreover, there is an emerging concern during pregnancy and lactation, when a woman needs additional iodine in order to have adequate supplies for both her own and her baby's needs. In the UK, organic milk has a significantly lower iodine concentration, compared to non-organic milk, and pregnant women who switch to organic milk are likely to have a reduced iodine intake $[37,40]$. Similarly, the risk of iodine deficiency has been observed among pregnant and childbearing aged women in the USA and Iceland, who do not consume milk and dairy products [46,47]. The present study indicates that lactating mothers who received iodine fortified milk containing $77.5 \mu \mathrm{g}$ iodine/ $100 \mathrm{~mL}$ daily, had higher urinary and breast milk iodine concentrations, compared to controls.

Based on the current evidence, it appears that, in some countries, the iodine requirements of the most vulnerable groups, i.e., pregnant and lactating women, and children aged 6-24 months, are not always adequately met by iodized salt; to address this issue, in 2007, WHO/ICCIDD/UNICEF issued a joint statement on "Reaching Optimal Iodine Nutrition in Pregnant and Lactating Women and Young Children", recommending that, besides strengthening universal salt iodization programs, additional complementary strategies such as iodine supplements, should be considered to ensure optimal iodine nutrition for these groups [48]. Moreover, the American Thyroid Association and the Endocrine Society $[30,31]$ recommend that pregnant and lactating women take $150 \mu \mathrm{g}$ iodine in daily prenatal vitamin/mineral supplements. The median urinary iodine at the baseline of the current study, in both the iodine fortified milk and control groups, also denoted suboptimal iodine nutrition among lactating mothers, emphasizing the necessity of iodine supplementation during lactation. Iodine supplementation with daily iodine fortified milk containing $150 \mu \mathrm{g}$ iodine per cup, ensured adequate iodine status in lactating mothers, as confirmed by the median urinary and breast milk values.

The main challenge in using median urinary iodine in infants is the difficulty faced in sample collection; hence, the best criteria for assessing iodine status have not yet been established, due to a lack of sufficient data for urinary iodine levels in this age group [8]. On the other hand, it is well-known that maternal iodine sufficiency is particularly important for exclusively breastfed infants, for whom breast milk is the sole source of iodine nutrition during a critical period of growth and development. Hence, on a biological basis, it could be expected that a positive association between urinary iodine in mothers, and exclusively breastfed infants, could be found [36]. However, our findings demonstrate that, despite decreased urinary and breast iodine levels among lactating mothers of the control group during the period of study, the iodine nutrition status of their infants was within optimal levels; moreover, the urinary iodine of the infants did not show any differences between groups, indicating that a compensatory mechanism in the mammary glands probably provides iodine enriched milk to infants. Another explanation for this finding can be attributed to the higher levels of urinary iodine in the intervention group at the baseline, which may dilute the effect of iodine fortified milk on infant urinary iodine.

Furthermore, it is worth mentioning that young children are vulnerable to excessive iodine exposure, since their thyroid gland is more susceptible to the inhibitory effect of high iodine doses than the adult gland. Thyroid disturbances, i.e., subclinical hypothyroidism and overt hypothyroidism, 
have been reported in studies in which newborns and infants were exposed to an excessive iodine intake [49]. For instance, in Japan and China, a transient elevation of thyrotropin was reported in some neonates born to mothers chronically exposed to high doses of iodine, mainly from foods and drinking water [50,51]. Also, in Nepal, a prevalence of $7.4 \%$ subclinical hypothyroidism and $<1 \%$ overt hypothyroidism was reported among infants aged 6-24 months who were exposed to an excessive iodine intake [52]. Hence, with respect to high levels of iodine in fortified milk in the present study, caution should be taken when applying these results in regions with a high daily per capita consumption of milk.

The main strengths of this research were: An investigation of the effect of iodine fortified milk on the iodine status of lactating mothers and their infants in an area with a successful salt iodization program, which is the first of its kind; the inclusion of a control group which only received iodized salt; and several measurements of breast milk and urinary iodine concentrations at different time points during the period of supplementation. However, the limitations of the present study are that we could not assess the effects of iodine fortified milk during the entire six month exclusive breastfeeding period, for further confirmation of our results; iodine concentration was measured in single spot urine and breast milk samples, which may not reflect the true iodine status in mothers and their infants. Although thyroglobulin has been reported to be a useful biomarker in populations, thyroglobulin was not measured in our study $[53,54]$ and we were unable to estimate dietary iodine intakes through the amount of iodized salt consumption as the main dietary source of iodine in Iran. Also, we had to assign the lactose intolerant mothers to the control group. However, the randomization and findings of the study do not seem to be affected, due to the small number of these mothers $(n=3)$.

\section{Conclusions}

Findings of the current study indicate that, in an area with a successful salt iodization program, lactating mothers require additional iodine through iodine fortified foods or iodine supplements. Our results also show that the supplementation of lactating mothers with daily iodine fortified milk containing $150 \mu \mathrm{g}$ iodine per cup, can ensure iodine nutrition adequacy; however, iodine fortified milk had no effect on the iodine status of infants, who had iodine sufficient status due to the high iodine concentrating capacity in the mammary gland. It seems that iodine fortified milk, in addition to iodized salt, can be considered a good dietary source to ensure iodine sufficiency during the lactation period.

Acknowledgments: This study was supported by a financial grant from the Research Institute of Endocrine Sciences, Shahid Beheshti University of Medical Sciences. The authors express their appreciation and gratitude to Niloofar Shiva for critical editing of English grammar and syntax of the manuscript.

Author Contributions: P.N. contributed to the design, data analysis and writing, reading, and final approval of the manuscript; P.M. contributed to the design of the study and the writing, reading, and final approval of the manuscript; Z.T. contributed to the statistical analysis and writing, reading, and final approval of the manuscript; M.H., H.D. and F.A. contributed to the design of the study and writing, reading, and final approval of the manuscript.

Conflicts of Interest: The authors declare no conflict of interest.

\section{References}

1. Delange, F. The role of iodine in brain development. Proc. Nutr. Soc. 2000, 59, 75-79. [CrossRef] [PubMed]

2. Zimmermann, M.B. The role of iodine in human growth and development. Semin. Cell Dev. Biol. 2011, 22, 645-652. [CrossRef] [PubMed]

3. Bath, S.C.; Steer, C.D.; Golding, J.; Emmett, P.; Rayman, M.P. Effect of inadequate iodine status in UK pregnant women on cognitive outcomes in their children: Results from the Avon Longitudinal Study of Parents and Children (ALSPAC). Lancet 2013, 382, 331-337. [CrossRef]

4. Delange, F. Iodine deficiency as a cause of brain damage. Postgrad. Med. J. 2001, 77, 217-220. [CrossRef] [PubMed]

5. Zimmermann, M.B. The adverse effects of mild-to-moderate iodine deficiency during pregnancy and childhood: A review. Thyroid 2007, 17, 829-835. [CrossRef] [PubMed] 
6. Zimmermann, M.B. The effects of iodine deficiency in pregnancy and infancy. Paediatr. Perinat. Epidemiol. 2012, 26 (Suppl. S1), 108-117. [CrossRef] [PubMed]

7. United Nations International Children's Emergency Fund (UNICEF). The State of the World's Children 2009: Maternal and Newborn Health: Unicef; UNICEF: New York, NY, USA, 2008.

8. World Health Organization. Assessment of Iodine Deficiency Disorders and Monitoring Their Elimination: A Guide for Programme Managers. 2007. Available online: whqlibdoc.who.int/publications/2007/ 9789241595827_eng.pdf (accessed on 30 October 2016).

9. World Health Organization. Salt as a Vehicle for Fortification; Report of a WHO Expert Consultation; WHO: Geneva, Switzerland, 2007.

10. Charlton, K.E.; Jooste, P.L.; Steyn, K.; Levitt, N.S.; Ghosh, A. A lowered salt intake does not compromise iodine status in Cape Town, South Africa, where salt iodization is mandatory. Nutrition 2013, 29, 630-634. [CrossRef] [PubMed]

11. Johner, S.A.; Gunther, A.L.; Remer, T. Current trends of 24-h urinary iodine excretion in German schoolchildren and the importance of iodised salt in processed foods. Br. J. Nutr. 2011, 106, 1749-1756. [CrossRef] [PubMed]

12. Nazeri, P.; Mirmiran, P.; Mehrabi, Y.; Hedayati, M.; Delshad, H.; Azizi, F. Evaluation of iodine nutritional status in Tehran, Iran: Iodine deficiency within iodine sufficiency. Thyroid 2010, 20, 1399-1406. [CrossRef] [PubMed]

13. Tayie, F.A.; Jourdan, K. Hypertension, dietary salt restriction, and iodine deficiency among adults. Am. J. Hypertens. 2010, 23, 1095-1102. [CrossRef] [PubMed]

14. Andersson, M.; Aeberli, I.; Wust, N.; Piacenza, A.M.; Bucher, T.; Henschen, I.; Haldimann, M.; Zimmermann, M.B. The Swiss iodized salt program provides adequate iodine for school children and pregnant women, but weaning infants not receiving iodine-containing complementary foods as well as their mothers are iodine deficient. J. Clin. Endocrinol. Metab. 2010, 95, 5217-5224. [CrossRef] [PubMed]

15. Brough, L.; Jin, Y.; Shukri, N.H.; Wharemate, Z.R.; Weber, J.L.; Coad, J. Iodine intake and status during pregnancy and lactation before and after government initiatives to improve iodine status, in Palmerston North, New Zealand: A pilot study. Matern. Child Nutr. 2015, 11, 646-655. [CrossRef] [PubMed]

16. Verd, S.; Aramburu, A.; Carreras, G. Iodine supplementation for lactation: Time for tailoring treatments targeted to specific subgroups. J. Paediatr. Child Health 2013, 49, E353-E354. [CrossRef] [PubMed]

17. Cressey, P. Iodine content of New Zealand dairy products. J. Food Comp. Anal. 2003, 16, 25-36. [CrossRef]

18. Dahl, L.; Johansson, L.; Julshamn, K.; Meltzer, H.M. The iodine content of Norwegian foods and diets. Public Health Nutr. 2004, 7, 569-576. [CrossRef] [PubMed]

19. Guyot, H.; Saegerman, C.; Lebreton, P.; Sandersen, C.; Rollin, F. Epidemiology of trace elements deficiencies in Belgian beef and dairy cattle herds. J. Trace Elem. Med. Biol. 2009, 23, 116-123. [CrossRef] [PubMed]

20. Johner, S.A.; Thamm, M.; Nothlings, U.; Remer, T. Iodine status in preschool children and evaluation of major dietary iodine sources: A German experience. Eur. J. Nutr. 2013, 52, 1711-1719. [CrossRef] [PubMed]

21. Li, M.; Waite, K.V.; Ma, G.; Eastman, C.J. Declining iodine content of milk and re-emergence of iodine deficiency in Australia. Med. J. Aust. 2006, 184, 307. [PubMed]

22. Pearce, E.N.; Pino, S.; He, X.; Bazrafshan, H.R.; Lee, S.L.; Braverman, L.E. Sources of dietary iodine: Bread, cows' milk, and infant formula in the Boston area. J. Clin. Endocrinol. Metab. 2004, 89, 3421-3424. [CrossRef] [PubMed]

23. Rasmussen, L.B.; Ovesen, L.; Bulow, I.; Jorgensen, T.; Knudsen, N.; Laurberg, P.; Pertild, H. Dietary iodine intake and urinary iodine excretion in a Danish population: Effect of geography, supplements and food choice. Br. J. Nutr. 2002, 87, 61-69. [CrossRef] [PubMed]

24. Jones, E.; McLean, R.; Davies, B.; Hawkins, R.; Meiklejohn, E.; Ma, Z.F.; Skeaff, S. Adequate Iodine Status in New Zealand School Children Post-Fortification of Bread with Iodised Salt. Nutrients 2016, 8, 298. [CrossRef] [PubMed]

25. Girelli, M.E.; Coin, P.; Mian, C.; Nacamulli, D.; Zambonin, L.; Piccolo, M.; Vianello-Dri, A.; Gottardo, F.; Busnardo, B. Milk represents an important source of iodine in schoolchildren of the Veneto region, Italy. J. Endocrinol. Investig. 2004, 27, 709-713. [CrossRef] [PubMed]

26. Soriguer, F.; Gutierrez-Repiso, C.; Gonzalez-Romero, S.; Olveira, G.; Garriga, M.J.; Velasco, I.; Santiago, P.; de Escobar, G.M.; Garcia-Fuentes, E. Iodine concentration in cow's milk and its relation with urinary iodine concentrations in the population. Clin. Nutr. 2011, 30, 44-48. [CrossRef] [PubMed] 
27. Azizi, F.; Mehran, L.; Sheikholeslam, R.; Ordookhani, A.; Naghavi, M.; Hedayati, M.; Padyab, M.; Mirmiran, P. Sustainability of a well-monitored salt iodization program in Iran: Marked reduction in goiter prevalence and eventual normalization of urinary iodine concentrations without alteration in iodine content of salt. J. Endocrinol. Investig. 2008, 31, 422-431. [CrossRef] [PubMed]

28. Azizi, F.; Sheikholeslam, R.; Hedayati, M.; Mirmiran, P.; Malekafzali, H.; Kimiagar, M.; Pajouhi, M. Sustainable control of iodinedeficiency in Iran: Beneficial results of the implementation of the mandatory law on salt iodization. J. Endocrinol. Investig. 2002, 25, 409-413. [CrossRef] [PubMed]

29. Caldwell, K.L.; Pan, Y.; Mortensen, M.E.; Makhmudov, A.; Merrill, L.; Moye, J. Iodine status in pregnant women in the National Children's Study and in U.S. women (15-44 years), National Health and Nutrition Examination Survey 2005-2010. Thyroid 2013, 23, 927-937. [CrossRef] [PubMed]

30. De Groot, L.; Abalovich, M.; Alexander, E.K.; Amino, N.; Barbour, L.; Cobin, R.H.; Eastman, C.J.; Lazarus, J.H.; Luton, D.; Mandel, S.J.; et al. Management of thyroid dysfunction during pregnancy and postpartum: An Endocrine Society clinical practice guideline. J. Clin. Endocrinol. Metab. 2012, 97, 2543-2565. [CrossRef] [PubMed]

31. Stagnaro-Green, A.; Abalovich, M.; Alexander, E.; Azizi, F.; Mestman, J.; Negro, R.; Nixon, A.; Pearce, E.N.; Soldin, O.P.; Sullivan, S.; et al. Guidelines of the American Thyroid Association for the diagnosis and management of thyroid disease during pregnancy and postpartum. Thyroid 2011, 21, 1081-1125. [CrossRef] [PubMed]

32. Norouzian, M.; Valizadeh, R.; Azizi, F.; Hedayati, M.; Naserian, A.; Shahroodi, F.E. The effect of feeding different levels of potassium iodide on performance, T3 and T4 concentrations and iodine excretion in Holstein dairy cows. J. Anim. Vet. Adv. 2009, 8, 111-114.

33. Norouzian, M.A. Iodine in raw and pasteurized milk of dairy cows fed different amounts of potassium iodide. Biol. Trace Elem. Res. 2011, 139, 160-167. [CrossRef] [PubMed]

34. Hedayati, M.; Khazan, M.; Yaghmaee, P.; Yeghaneh, M.Z.; Behdadfar, L.; Daneshpour, M.S. Rapid microwave digestion and microplate reading format method for urinary iodine determination. Clin. Chem. Lab. Med. 2011, 49, 281-284. [CrossRef] [PubMed]

35. Hedayati, M.; Ordookhani, A.; Daneshpour, M.S.; Azizi, F. Rapid acid digestion and simple microplate method for milk iodine determination. J. Clin. Lab. Anal. 2007, 21, 286-292. [CrossRef] [PubMed]

36. Azizi, F.; Smyth, P. Breastfeeding and maternal and infant iodine nutrition. Clin. Endocrinol. (Oxf.) 2009, 70, 803-809. [CrossRef] [PubMed]

37. Bath, S.C.; Button, S.; Rayman, M.P. Iodine concentration of organic and conventional milk: Implications for iodine intake. Br. J. Nutr. 2012, 107, 935-940. [CrossRef] [PubMed]

38. Watutantrige Fernando, S.; Barollo, S.; Nacamulli, D.; Pozza, D.; Giachetti, M.; Frigato, F.; Redaelli, M.; Zagotto, G.; Girelli, M.E.; Mantero, F.; et al. Iodine status in schoolchildren living in northeast Italy: The importance of iodized-salt use and milk consumption. Eur. J. Clin. Nutr. 2013, 67, 366-370. [CrossRef] [PubMed]

39. Rasmussen, L.B.; Carle, A.; Jorgensen, T.; Knuthsen, P.; Krejbjerg, A.; Perrild, H.; Bjergved, L.; Sloth, J.J.; Laurberg, P.; Ovesen, L. Iodine excretion has decreased in Denmark between 2004 and 2010-The importance of iodine content in milk. Br. J. Nutr. 2014, 112, 1993-2001. [CrossRef] [PubMed]

40. Payling, L.M.; Juniper, D.T.; Drake, C.; Rymer, C.; Givens, D.I. Effect of milk type and processing on iodine concentration of organic and conventional winter milk at retail: Implications for nutrition. Food Chem. 2015, 178, 327-330. [CrossRef] [PubMed]

41. Shakerian, A. Iodine Determination in Raw Cow's Milk in Iran. JFBT 2014, 4, 13-20.

42. Rasmussen, L.B.; Carle, A.; Jorgensen, T.; Knudsen, N.; Laurberg, P.; Pedersen, I.B.; Perrild, H.; Vejbjerg, P.; Ovesen, L. Iodine intake before and after mandatory iodization in Denmark: Results from the Danish Investigation of Iodine Intake and Thyroid Diseases (DanThyr) study. Br. J. Nutr. 2008, 100, 166-173. [CrossRef] [PubMed]

43. Rasmussen, L.B.; Jorgensen, T.; Perrild, H.; Knudsen, N.; Krejbjerg, A.; Laurberg, P.; Pedersen, I.B.; Bjergved, L.; Ovesen, L. Mandatory iodine fortification of bread and salt increases iodine excretion in adults in Denmark-A 11-year follow-up study. Clin. Nutr. 2014, 33, 1033-1040. [CrossRef] [PubMed]

44. Brantsaeter, A.L.; Abel, M.H.; Haugen, M.; Meltzer, H.M. Risk of suboptimal iodine intake in pregnant Norwegian women. Nutrients 2013, 5, 424-440. [CrossRef] [PubMed] 
45. Brantsaeter, A.L.; Haugen, M.; Julshamn, K.; Alexander, J.; Meltzer, H.M. Evaluation of urinary iodine excretion as a biomarker for intake of milk and dairy products in pregnant women in the Norwegian Mother and Child Cohort Study (MoBa). Eur. J. Clin. Nutr. 2009, 63, 347-354. [CrossRef] [PubMed]

46. Gunnarsdottir, I.; Gustavsdottir, A.G.; Steingrimsdottir, L.; Maage, A.; Johannesson, A.J.; Thorsdottir, I. Iodine status of pregnant women in a population changing from high to lower fish and milk consumption. Public Health Nutr. 2013, 16, 325-329. [CrossRef] [PubMed]

47. Perrine, C.G.; Herrick, K.; Serdula, M.K.; Sullivan, K.M. Some subgroups of reproductive age women in the United States may be at risk for iodine deficiency. J. Nutr. 2010, 140, 1489-1494. [CrossRef] [PubMed]

48. Untoro, J.; Mangasaryan, N.; de Benoist, B.; Darnton-Hill, I. Reaching optimal iodine nutrition in pregnant and lactating women and young children: Programmatic recommendations. Public Health Nutr. 2007, 10, 1527-1529. [CrossRef] [PubMed]

49. Aakre, I.; Strand, T.A.; Bjøro, T.; Norheim, I.; Barikmo, I.; Ares, S.; Alcorta, M.D.; Henjum, S. Thyroid Function among Breastfed Children with Chronically Excessive Iodine Intakes. Nutrients 2016, 8, 398. [CrossRef] [PubMed]

50. Fuse, Y.; Ohashi, T.; Yamaguchi, S.; Yamaguchi, M.; Shishiba, Y.; Irie, M. Iodine status of pregnant and postpartum Japanese women: Effect of iodine intake on maternal and neonatal thyroid function in an iodine-sufficient area. J. Clin. Endocrinol. Metab. 2011, 96, 3846-3854. [CrossRef] [PubMed]

51. Chen, W.; Sang, Z.; Tan, L.; Zhang, S.; Dong, F.; Chu, Z.; Wei, W.; Zhao, N.; Zhang, G.; Yao, Z.; et al. Neonatal thyroid function born to mothers living with long-term excessive iodine intake from drinking water. Clin. Endocrinol. (Oxf.) 2015, 83, 399-404. [CrossRef] [PubMed]

52. Nepal, A.K.; Suwal, R.; Gautam, S.; Shah, G.S.; Baral, N.; Andersson, M.; Zimmermann, M.B. Subclinical Hypothyroidism and Elevated Thyroglobulin in Infants with Chronic Excess Iodine Intake. Thyroid 2015, 25, 851-859. [CrossRef] [PubMed]

53. Ma, Z.F.; Skeaff, S.A. Thyroglobulin as a biomarker of iodine deficiency: A review. Thyroid 2014, 24, 1195-1209. [CrossRef] [PubMed]

54. Ma, Z.F.; Venn, B.J.; Manning, P.J.; Cameron, C.M.; Skeaff, S.A. Iodine Supplementation of Mildly Iodine-Deficient Adults Lowers Thyroglobulin: A Randomized Controlled Trial. J. Clin. Endocrinol. Metab. 2016, 101, 1737-1744. [CrossRef] [PubMed] 